\title{
Review of the evidence base for ecosystem-based approaches for adaptation to climate change
}

\author{
Robert Munroe ${ }^{1 *}$, Dilys Roe ${ }^{2}$, Nathalie Doswald ${ }^{3}$, Tom Spencer ${ }^{4}$, Iris Möller ${ }^{4}$, Bhaskar Vira ${ }^{5}$, Hannah Reid ${ }^{2}$, \\ Andreas Kontoleon ${ }^{6}$, Alessandra Giuliani ${ }^{2}$, Ivan Castelli ${ }^{3}$ and Jen Stephens ${ }^{7}$
}

\begin{abstract}
Background: Ecosystem-based approaches for adaptation (EbA) integrate the use of biodiversity and ecosystem services into an overall strategy for helping people adapt to climate change. To date, insight into these approaches has often been based on reports from isolated anecdotal case studies. Although these are informative, and provide evidence that people are using ecosystems to adapt, they provide rather limited insight in terms of measuring and evaluating the effectiveness of EbA, especially when compared with technical or structural adaptation interventions. The body of scientific evidence indicating how effective such approaches are is lacking in some aspects. Where evidence does exist it is often dispersed across a range of related fields, such as natural resource management, disaster risk reduction and agroecology. To date, there has been little attempt to systematically assemble and analyse this evidence. Therefore, the current state of evidence regarding the merits or otherwise of EbA is unknown and it has not been possible to identify prevailing knowledge gaps to inform research and analysis, which will enable policymakers to compare EbA with other adaptation options.

Methods: This protocol details the methodology to be used to conduct a systematic map of peer-reviewed published journal papers and a limited selection of grey literature, to give a methodical overview of the state of the evidence base for EbA effectiveness, and to identify the current knowledge gaps. It addresses the following question: What is the state of the evidence base regarding the ability of ecosystem-based approaches for adaptation to help people adapt to the impacts of climate change?
\end{abstract}

Keywords: Climate change, Adaptation, Ecosystem management, Conservation, Biodiversity, Ecosystem services, Systematic map, Ecosystem-based approaches for adaptation, Ecosystem-based adaptation

\section{Background}

Adaptation to climate change may be achieved in many different ways. One way is through ecosystem-based approaches for adaptation (EbA) - defined by the Convention on Biological Diversity (CBD) $2^{\text {nd }}$ Ad Hoc Technical Expert Group on Biodiversity and Climate Change [1] as 'the use of biodiversity and ecosystem services to help people adapt to the adverse effects of climate change'. This definition was elaborated by the CBD $10^{\text {th }}$ Conference of the Parties (CoP) in October 2010, as including 'sustainable management, conservation and restoration of ecosystems, as part of an overall adaptation strategy that takes into account the multiple social, economic and cultural co-benefits for local communities' [2].

\footnotetext{
* Correspondence: robert.munroe@birdlife.org

'BirdLife International, Wellbrook Court, Girton Road, Cambridge CB3 ONA, UK Full list of author information is available at the end of the article
}

EbA is being enthusiastically promoted by conservation and development organisations that recognise the integral relationship between ecosystems and livelihoods and the threat that climate change poses to these. As a result there are numerous anecdotal case studies of its apparent success describing how local communities are already practicing EbA [3-6]. However, such case studies largely lack a scientific assessment that provides reliable and robust evidence indicating how effective these approaches are [7]. In particular, there are very few quantitative assessments of EbA effectiveness which use controls to examine the impact of the intervention, and few which provide plausible counterfactual arguments about likely causal mechanisms involved. There are also few case studies on either the cost-effectiveness of EbA or on the assessment of its social value. Importantly, the UNFCCC Secretariat [8] notes that, 'Besides financial

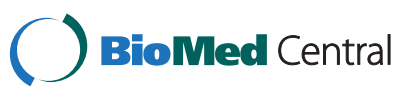


and economic assessments, social appraisal is crucial in any assessment of costs and benefits of adaptation options, because the impacts of climate change often disproportionately affect the most vulnerable communities and groups.'

In other cases, empirical material that is relevant to EbA is dispersed across a range of related fields such as natural resource management, disaster risk reduction and agroecology. Evidence and lessons learnt from these disciplines have not previously been collated to inform EbA, nor have they been consolidated so that policymakers can compare EbA with other possible adaptation options.

Beyond the gaps in the evidence base, a further difficulty has been the lack of general consensus on what successful or effective adaptation actually means - although assessment frameworks are now emerging [9-12].

This protocol details the methodology to be used to conduct a systematic map of peer-reviewed published journal papers and a limited selection of grey literature (i.e. published and unpublished documents that do not pass through the scientific peer-review system), to give a methodical overview of the state of the evidence base for EbA effectiveness, and to identify the current knowledge gaps.

\section{Objective of the review}

This review seeks to address the primary question: What is the state of the evidence base regarding the ability of ecosystem-based approaches for adaptation to help people adapt to the impacts of climate change? (See 'Table 1 - Elements of the systematic map question'). The secondary question is: What are the critical knowledge gaps in the evidence?

\section{Methods \\ Searches \\ Search terms}

Experts were invited to a workshop in Cambridge from organisations working on EbA or related activities that BirdLife International have had exposure to, or worked with, on ecosystems and adaptation during the UNFCCC negotiations. Focus groups were held during this expert workshop to guide the identification of key terms to be used for literature searches of peer-reviewed and grey literature. As a starting point, search terms used in a recent study by CIFOR (personal communication with
Emilia Pramova, see 'Table 2 - CIFOR study search terms') were built upon to meet project needs.

Concern about climate change - and how to adapt to it - has only received widespread international political attention in the last two decades. However, people have been adapting to, and managing their environment and natural resource use in response to, climatic variability, climatic shocks and change for centuries. Many of the impacts we can expect to see because of climate change will be the same as those associated with climate variability and shocks [13], so this wider literature presents a large relevant knowledge base to draw upon. Our selection of search terms to be used also covered those associated with climatic variability, extremes or other natural hazards that can provide analogues to events linked to climate change.

Trial literature searches were conducted through the ISI Web of Knowledge (WoK: http://wok.mimas.ac.uk/) to hone search terms by testing whether a short list of papers known by experts to contain information relevant to this review appeared in the outputs of the search.

The resulting final search terms (see 'Table 3 - Search term scoping and evolution and search string') have been selected to provide broad, but manageable coverage related to the review questions (see 'Objective of the review' above). Four sets of search terms will be used with individual terms (and Wildcard symbols $\left({ }^{*}\right)$ where appropriate) separated by Boolean "OR" operators and sets combined using "AND". A fifth set will be used and combined with "AND NOT" (to exclude solely ecosystembased approaches for climate change mitigation, and other mitigation studies that refer to land use emissions or mitigation approach (e.g. renewable energy) impacts on the environment). Searches will be conducted in English only.

\section{Publication database searches}

Two databases will be searched: WoK and Scopus. This follows the recommendation of the Centre for Evidencebased Conservation [14] who suggest using more than one database of peer-reviewed papers. Both these databases cover science (including life science, chemistry, physics, mathematics, biology, and environmental science) and social sciences (although WoK does so regarding the latter to a greater degree) [15]. In each database the search will be refined by selecting key subject areas. For WoK these will be: "environmental sciences and ecology", "agriculture", "water resources", "forestry",

Table 1 Elements of the systematic map question

\begin{tabular}{|c|c|c|c|}
\hline Subject & Intervention & Comparators & Outcomes \\
\hline $\begin{array}{l}\text { Human individuals, groups, } \\
\text { communities and economic } \\
\text { sectors (e.g. agriculture, water, } \\
\text { forestry, transport) }\end{array}$ & $\begin{array}{l}\text { Ecosystem-based approaches for adaptation } \\
\text { - the use of biodiversity and ecosystem } \\
\text { services to help people adapt to the } \\
\text { adverse effects of climate change }\end{array}$ & $\begin{array}{l}\text { No adaptation intervention, or an } \\
\text { alternative adaptation intervention } \\
\text { to ecosystem-based approaches } \\
\text { for adaptation }\end{array}$ & $\begin{array}{l}\text { Human adaptation to climate } \\
\text { change, variability, extremes or } \\
\text { other natural hazards that could } \\
\text { be linked to climate }\end{array}$ \\
\hline
\end{tabular}




\section{Table 2 CIFOR study search terms}

\begin{tabular}{ll}
\hline Original search & adaptation OR adaptive OR vulnerable OR vulnerability OR coping OR resilience OR resilient OR adapt OR cope \\
terms & OR "disaster risk reduction" \\
AND & "climate change" OR "climate variability" OR "climate hazard" OR "extreme weather" OR "natural hazard" \\
OR disaster OR flood OR drought OR hurricane OR storm OR cyclone OR "sea level rise" OR "irregular \\
rainfall" OR "intense rainfall" \\
AND \\
ecosystem OR wetland OR forest OR woodland OR dryland OR grassland OR "coral reef" OR biodiversity OR coastal \\
OR mangrove OR tree OR agro forestry \\
AND \\
people OR society OR community OR city OR settlement OR social OR population OR livelihood OR household \\
OR village OR farmer OR poverty OR rural \\
"climate change" OR "climate variability" OR "climate hazard" OR "extreme weather" OR "natural hazard" OR disaster \\
OR flood OR drought OR hurricane OR storm OR cyclone OR "sea level rise" OR "irregular rainfall" OR "intense rainfall" \\
AND \\
"ecosystem-based adaptation" OR "ecosystem services" OR "green infrastructure" OR "ecological infrastructure" \\
OR "soft infrastructure" OR "natural infrastructure" \\
AND \\
rearch terms \\
People OR society OR community OR city OR settlement OR social OR population OR livelihood OR city
\end{tabular}

"engineering", "biodiversity conservation", "science technology other topics", and "social science other topics"; and for Scopus: "environmental science", "earth and planetary sciences", "agricultural and biological sciences", "social sciences”, "engineering”, "energy", "economics, econometrics and finance", and "multidisciplinary”. The Field Code ' 'Topic' does not exist on Scopus, so the nearest equivalent, 'abstract' (returns searches where the search terms are found in the abstract of the papers), will be used as a replacement (see 'Table 3 Search term scoping and evolution and search string'). The results from the Scopus search will be combined with the WoK search in Reference Manager and overlaps will be excluded.

\section{Internet searches}

In addition, to WoK and Scopus, Google Scholar will be searched using a more limited range of terms from the four sets of search terms. The first 50 'hits' will be compared with the WoK and Scopus search returns to test their comprehensiveness. References returned by the Google Scholar search, but not found in the WoK and Scopus searches, will be added to the reference list.

\section{Specialist searches - searches for grey literature}

A limited selection of 'grey' literature (i.e. published and unpublished documents that do not pass through the scientific peer-review system) will be identified by going directly to relevant organisation websites informed by the list of relevant sources determined by expert input:
Action Aid

Adaptation Learning Mechanism

CARE International

Conservation International

Ecosystems and Livelihoods Adaptation Network

Global Environment Facility - Project Database

International Union for Conservation of Nature

Mercy Corps

Overseas Development Institute

ProAct Network

The Nature Conservancy

United Nations Convention on Biological Diversity

United Nations Convention to Combat Desertification

United Nations Development Programme

United Nations Environment Programme

United Nations Framework Convention on Climate

Change

United Nations Framework Convention on Climate

Change - Nairobi Work Programme Database on

Ecosystem-based approaches to adaptation

United Nations International Strategy for Disaster

Reducation

weAdapt

Wetlands International

World Bank

World Bank - Project Database

World Conservation Society

World Resources Institute

World Resources Institute - World Resources Report

World Wildlife Fund

Finally, participants in the expert workshop will be asked to review the list of references generated by the 
Table 3 Search term scoping and evolution and search string Search String

\section{Number of hits (Web of Knowledge- $23^{\text {rd }}$ August 2011) \\ Change to syntax}

1. Topic $=($ climat* change OR "global warming" OR climat* variability OR "climate hazard" OR "extreme weather" OR "natural hazard" OR disaster OR flood OR tsunami OR drought OR hurricane OR storm OR cyclone OR

a) 33223

b) 24331 b) Refined by: Subject Areas= (ENVIRONMENTAL SCIENCES ECOLOGY OR AGRICULTURE OR WATER RESOURCES OR BIODIVERSITY CONSERVATION OR FORESTRY OR ENGINEERING OR SOCIAL SCIENCES OTHER TOPICS) OR "green infrastructure" OR "ecological infrastructure" OR "soft infrastructure" OR "natural capital" OR "natural resources" OR "natural infrastructure" OR "ecosystem approach" OR "ecosystem goods" OR ecosystem OR vegetation OR wetland OR forest OR woodland OR dryland OR grassland OR "coral reef" OR biodiversity OR coast* OR mangrove OR "sea grass" OR watershed) AND Topic=(people OR society OR community OR city OR settlement OR social OR population OR livelihood* OR sector OR forestry $O R$ water $O R$ fishing $O R$ dryland $O R$ agricultur* OR poverty $O R$ village OR rural OR household OR farmer) AND Topic=(adapt* OR vulnerab* OR cop* OR disaster risk reduction OR "risk mitigation" OR "risk management" OR resilie* OR manag* OR "ecosystem-based adaptation" OR "natural resource management" OR "ecosystem-based approaches to adaptation" OR "ecosystem-based approaches for adaptation")

2. Topic=("climat* change" OR "global warming" OR "climat* variability" OR "climate hazard" OR "extreme weather" OR "natural hazard" OR disaster OR tsunami OR flood* OR drought OR hurricane OR storm OR cyclone OR "sea level rise" OR erosion OR mudslides OR landslides OR precipitation OR temperature OR "rainfall variability") AND Topic=("natural capital" OR "ecosystem services" OR "green infrastructure" OR "ecological infrastructure" OR "soft infrastructure" OR vegetation OR "natural infrastructure" OR "ecosystem goods" OR ecosystem OR wetland OR "natural resources" OR forest OR woodland OR dryland OR grassland OR "coral reef" OR biodiversity OR coast* OR mangrove OR tree OR "sea grass" OR watershed) AND Topic=(people OR society OR community OR city OR population OR livelihood OR sector OR forestry OR "water sector" OR "water management" OR "rainwater harvesting" OR fishing OR agricultur* OR village OR rural OR farmer) AND Topic=(adapt* OR vulnerab* OR cop* OR "sustainable management" OR protect* OR "disaster risk reduction" OR mitigation OR "risk management" OR resilie* OR "ecosystem-based adaptation" OR "ecosystem approach" OR "natural resource management" OR "ecosystem-based approaches to adaptation" OR "ecosystem-based approaches for adaptation")
4. Topic=("climat* change" OR "global warming" OR "climat* variability" OR "climate hazard" OR "extreme weather" OR "natural hazard" OR disaster OR tsunami OR flood OR drought OR hurricane OR storm OR cyclone OR "sea level rise" OR erosion OR mudslides OR landslides OR precipitation OR temperature) AND Topic=("natural capital" OR "ecosystem services" OR "green infrastructure" OR "ecological infrastructure" OR "soft infrastructure" OR vegetation OR "natural infrastructure" OR "ecosystem goods" OR ecosystem OR wetland OR "natural resources" OR forest OR woodland OR dryland OR grassland OR "coral reef" OR biodiversity OR coast* OR mangrove OR tree OR "sea grass" OR watershed) AND Topic=(people OR society OR community OR city OR population OR livelihood OR sector OR forestry OR "water sector" OR "water management" OR "rainwater harvesting" OR agroforestry OR fisheries OR agricultur* OR village OR rural OR farmer) AND Topic=(adapt* OR vulnerab* OR cop* OR "sustainable management" OR protect* OR "disaster risk reduction" OR mitigation OR "risk management" OR resilie* OR "ecosystem-based adaptation" OR "ecosystem approach" OR "natural resource management" OR "ecosystem-based approaches to adaptation" OR "ecosystem-based approaches for adaptation")

AND NOT Topic=(biofuel OR "carbon stock*" OR (stock AND carbon) OR "renewable energy" OR bioenergy OR

"alternative fuel" OR emissions)

$\begin{array}{ll}\text { a) } 14928 & \text { b) Took out rain* - replaced with } \\ \text { "rainfall variability" } & \\ \text { b) } 10630 & \text { Took out water - replaced with } \\ & \text { ORater sector" OR "water management" } \\ & \text { ORainwer harvesting" }\end{array}$

a) 14048

b) Added AND NOT Topic $=$ (biofuel OR "carbon stock" OR (stock AND carbon) OR "renewable energy" OR bioenergy OR "alternative fuel" OR emissions)

b) 9952 
Table 3 Search term scoping and evolution and search string (Continued)

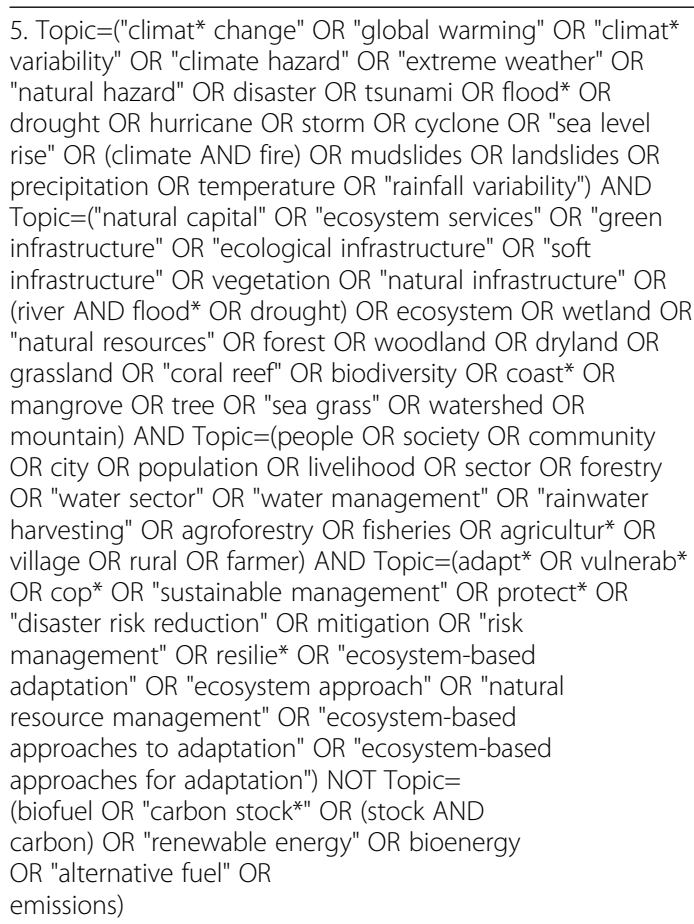

7. ABS("climat* change" OR "global warming" OR "climat* variability" OR "climate hazard" OR "extreme weather" OR "natural hazard" OR disaster OR (climate AND fire) OR tsunami OR flood* OR drought OR hurricane OR storm OR cyclone OR "sea level rise" OR mudslides OR landslides OR precipitation OR temperature OR "rainfall variability") a) 16206

b) 11110

b) Took out 'erosion' - too broad, hopefully captured by 'mudslides' and 'landslides' search terms.

Added fire term (fire AND climate) as a climate term otherwise wildfires related to increasing temperatures and decreasing precipitation may not be included in search results.

Took out "ecosystem goods" as this term refers to the outcomes of the management of ecosystem services rather than the object of management and disparate compared with the list.

Added other habitat types that were otherwise missing but made more specific 'mountain' OR (river AND flood* OR drought) a) 8275

b) 5682

3565
Took out fisheries - too broad, communities undertaking ecosystembased approaches for adaptation that improve the resilience of their fishing stocks should be captured by other search terms such as 'wetland', coral reef', 'ecosystem services', and 'natural resource', otherwise returning search results that include papers on specific fisheries important species, and climatic impacts on fisheries.

Replaced city with urban because the term 'city' was picking up specific places (ending up with more spurious entries) ather than the urban environment.

Took out community as it was causing confusion with the likes of 'communities of species'.

Replaced population with "human population" as it was causing confusion with the likes of 'genetic populations' and 'populations of species' 
Table 3 Search term scoping and evolution and search string (Continued)

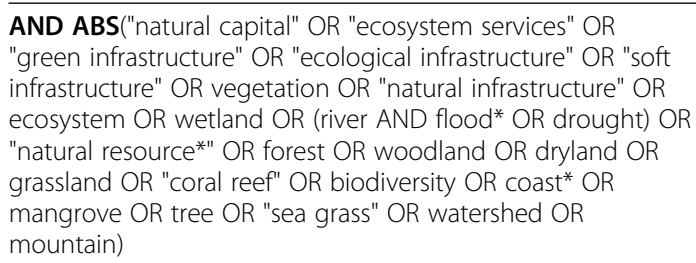

AND ABS(people OR "human population" OR livelihood OR sector OR forestry OR "water sector" OR "water management" OR "rainwater harvesting" OR agroforestry OR agricultur* OR village OR rural OR urban OR farmer)AND ABS(adapt* OR vulnerab* OR cop* OR resilie* OR

"sustainable management" OR "environment* management" OR "ecosystem-based management" OR "ecosystem based management" OR (disaster AND reduction) OR (climate OR risk AND mitigation) OR "risk management" OR "ecosystembased adaptation" OR "ecosystem approach" OR "natural resource management" OR "ecosystem-based approaches to adaptation" OR "ecosystem-based approaches for adaptation")

AND NOT ABS(biofuel OR "carbon stock*" OR (stock AND carbon) OR "renewable energy" OR bioenergy OR "alternative fuel" OR emissions)

AND (LIMIT-TO(SUBJAREA,"ENVI" ) OR LIMIT-TO

(SUBJAREA,"EART" ) OR LIMIT-TO(SUBJAREA,"AGRI" ) OR LIMIT-

TO(SUBJAREA,"SOCI" ) OR LIMIT-TO(SUBJAREA,"ENGI" ) OR

LIMIT-TO(SUBJAREA,"ENER" ) OR LIMIT-TO(SUBJAREA,"ECON" ) OR LIMIT-TO(SUBJAREA,"MULT" ))

peer-reviewed and grey literature searches to identify additional key references.

\section{Estimating the comprehensiveness of the search}

We consider that the search will be comprehensive as a result of combining objective database searches and subjective expert advice (including trial searches as described in the 'Search terms' section above, as well as a test Google Scholar search as described in the 'Internet searches' section above), and taking into account both peer-reviewed and grey literature.

Limitations of the review's comprehensiveness include that literature/topic review papers will be excluded (see 'Study inclusion/exclusion criteria' section below for reasoning) despite their possible use as a source of additional references. The comprehensiveness of the search could have been furthered by searching for relevant literature within the bibliographies of the captured literature.

The search will not include a body of relevant biophysical science literature (e.g. on intertidal vegetation controls on wave energy dissipation, erosion and sedimentation) as this does not make explicit links to human adaptation despite being relevant to such adaptation. This literature could provide significant information on biophysical thresholds or 'tipping points' that control the degree to which an ecosystem (and the services it provides to the community) can continue to act in that capacity under an increase in physical stress (e.g. climate change), and on boundary conditions (minimum size or the state of ecosystem necessary to provide adaptation benefits).

The comprehensiveness of the grey literature search will be negatively affected by the lack of a single comprehensive database/portal housing relevant grey literature documents. Moreover, our search will not include (because of time constraints) unpublished project documentation that is not available online.

\section{Study inclusion/exclusion criteria}

After combing search outputs from WoK and Scopus and removing duplicates, the inclusion/exclusion process will be undertaken through a stepwise process, by applying the primary inclusion and exclusion criteria (see 'Table 4 Primary inclusion and exclusion criteria') to: a) the article title, b) the abstract and c) the full text, of each of the articles ('articles' used hereafter to cover peer-reviewed published journal papers, grey literature and any papers/ literature which includes multiple studies/pieces of evidence which will be recorded separately - see 'Data extraction strategy' below for more information on multiple studies within the same source). Exclusion will be conservative during phase a) and b) if there is any doubt that the criteria for inclusion or exclusion are being met. Step a) will be undertaken by a single reviewer, while step b) and c) will involve more than one reviewer.

Reviewer bias will be tested for at the start of the selection process of step b) with a Kappa analysis [14]. Two 
Table 4 Primary inclusion and exclusion criteria

Articles will be included in the review if they meet these criteria
Articles will be deliberately excluded if they meet these criteria (primary exclusion criteria)
1. Relevant subject(s): Human individuals, groups, communities and economic sectors (e.g. agriculture, water, forestry, transport).

2. Types of intervention: ecosystem-based approaches for adaptation as guided by the following list [1]:

- Sustainable water management where river basins, aquifers, flood plains and their associated vegetation provide water storage and flood regulation;

- Disaster-risk reduction where restoration of coastal habitats such as mangroves can be a particularly effective measure against storm-surges and coastal erosion;

- Sustainable management of grasslands and rangelands, to enhance pastoral livelihoods;

- Forest conservation and sustainable forest management - maintenance of nutrient and water flow and prevention of land slides

- Establishment of diverse agricultural systems, where using indigenous knowledge of specific crop and livestock varieties, maintaining genetic diversity of crops and livestock, and conserving diverse agricultural landscapes secures food provision in changing local climatic conditions;

- Establishing and effectively managing protected-area systems to ensure the continued delivery of ecosystem services that increase resilience to climate change.

3. Types of comparator: No adaptation intervention, or an alternative adaptation intervention to ecosystem-based approaches for adaptation.

\section{Irrelevant subject(s):}

- Evidence not related to climate (e.g. pollution)

- Evidence focussed on climate impacts rather than adaptation

- Evidence focussed on mitigation of climate change rather than adaptation

\section{Irrelevant interventions:}

- No substantial reference to biodiversity, ecosystem services or ecosystems

- Evidence focussed on ecological adaptation rather than human adaptation

\section{Lack of comparator/outcome:}

-Where no measure of success of the intervention (the measurement of the direct effectiveness of EbA in reducing vulnerability to climate change, variability, extremes or other natural hazards that could be linked to climate) was presented compared to no adaptation intervention, or an alternative adaptation intervention.

\section{Types of study:}

- Comparisons of modelling techniques

- Literature/topic review paper (on the assumption that this search should have captured the articles that relevant review papers use, and that depth of evidence in such papers is often not enough to fill in the Assessment Framework $)^{b}$

- Articles that were not published in English reviewers will review a common, random 10 per cent sample of the abstracts. Level of agreement between the number of articles rejected or accepted by the reviewers will be calculated using the Kappa statistic [16]. Values can range from +1 (perfect agreement) to -1 (strong disagreement) .

During step c), reasonable effort will be made to secure the relevant articles, contacting authors if necessary. However, it may not be feasible within the time and budget constraints to secure all articles (a list of these will be made available when the results are published).

In order to make the review manageable in the time available, secondary exclusion criteria have been developed. One set of articles excluded will be those focussed on 'maladaptation'. These studies typically give evidence on the negative impact of other types of adaptation (e.g. sea walls) on ecosystems and then suggest that using ecosystems would be a more appropriate form of response, rather than testing the effectiveness of the identified ecosystem-based approaches for adaptation. The other exclusion criteria have been based on the types of intervention. Specifically, articles covering traditional agricultural practices (such as minimal tillage, cropping date adjustment, water management like the creation of artificial ponds for water storage) without consideration of the surrounding ecosystem will be excluded. By contrast, agricultural practices that have the explicit objective of protecting the surrounding ecosystem to provide adaptation benefits will not be excluded (e.g. agroforestry, agrobiodiversity conservation, management of agricultural lands for watershed management/runoff management). Approaches focussed on urban interventions, 
such as urban green roofs, green infrastructure and green and blue space within a city, will be excluded. By contrast, urban approaches which consider a city's relationship with its surrounding ecosystem(s)/wider landscape will be included. This includes watershed management working towards providing protection to densely populated areas on floodplains or at the foot of steep hillsides.

These secondary exclusions criteria were based on the following:

- The role that biodiversity and ecosystems play in the adaptation approach are not always made clear in such studies.

Despite these exclusions, basic information such as climatic hazards/impacts addressed, location and ecosystem, will still be extracted from these articles (see questions outlined in the first section of the Assessment Framework [17] - see 'Data extraction strategy' section below) to allow the possibility for future assessments of those studies.

Furthermore, all of the articles identified prior to secondary exclusion will be recorded (and will be included in the published results) so that future reviewers can follow-up on these excluded articles if required.

For the grey literature, the primary and secondary exclusion criteria will be merged (because this will only be a limited selection of the grey literature) to become general exclusion criteria. Like the peer-reviewed literature, a stepwise process to inclusion/exclusion will be adopted: a) title and introduction, b) a scan of the full text and c) a read of the full text.

The number of articles found in the search and included at each inclusion/exclusion level will be reported in the published results.

\section{Study quality assessment}

The design of each included study will be recorded based on general categories, see 'Table 5 - Study quality assessment categories'), and qualitative detail on the measure of intervention success used. This will allow an overview to be given of the quality of included studies.

\section{Data extraction strategy}

An Assessment Framework has been developed to extract data from the studies that are reviewed [17] to enable critical appraisal. This consists of a series of 39 questions separated into 4 parts:

1) Basic information (including climate hazard/impact addressed, location, ecosystem, and adaptation target);

2) Description of evidence (including type and quality of evidence, and constituent parts of effectiveness addressed);

Table 5 Study quality assessment categories

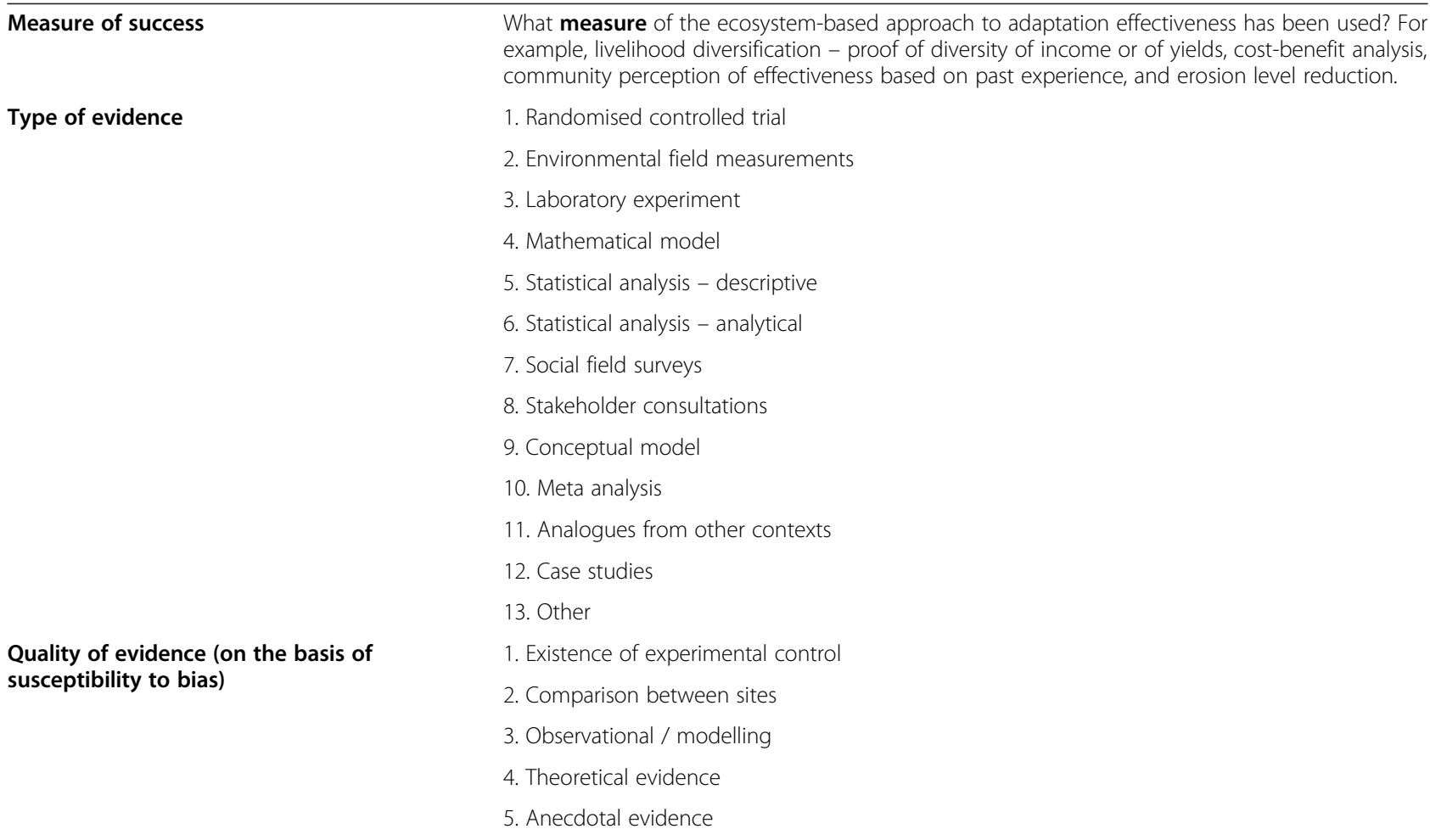


3) Detail of evidence (including measure of success used, result, and costs and benefits); and

4) Project design section for practical projects (including assessments undertaken, monitoring, and sustainability).

The questions (or variables) included in the framework were identified at the expert workshop through discussions on what information is required by policy makers to make informed decisions about the use of EbA as an adaptation option in any given context. This expert opinion was supplemented through a review of the monitoring and evaluation frameworks of a number of major climate change adaptation funds $[12,18]$ and other adaptation evaluation literature $[9,19]$.

Data input will be for the most part categorical (i.e. follow a numerical coding). This will allow for the quantitative description of the results. Some qualitative descriptive elements are also requested by the framework to capture fuller details where required. Attempts to minimise reviewer subjectivity will be made by using limited free text answers to questions, by asking reviewers to select from lists of pre-defined answers, and by holding reviewer meetings on a regular basis to discuss queries on data extraction to ensure consistency of input.

Data will be recorded in a dedicated Excel spreadsheet ('logbook', see 'Additional file 1 - Excel blank logbook'). Each study/source of evidence will be recorded in the logbook and allocated a unique article ID. Articles that include multiple studies/pieces of evidence (e.g. two or more case studies with the evidence presented separately for each) will be recorded by allocating a separate ID to each study within the article. The logbook columns correspond to the framework questions/evidence variables and separate worksheets correspond to the four discrete sections described above. More information on how to use the Assessment Framework and logbook is available in Munroe et al. [20].

\section{Data synthesis and presentation}

Descriptive and basic inferential statistics will be used to summarise quantitative trends in the information provided by the literature, mapping the quantity and quality of articles relevant to the question. An overview of the evidence will be given according to a variety of categories (see 'Table 6 - Categories of data analysed'), based on the Assessment Framework, to highlight knowledge gaps in the evidence base (the secondary question of the review). Implications of the state of the evidence base for policy, implementation and research related to EbA, as captured by the systematic map, will be given in the published results.

\section{Endnotes}

"Field Codes or "Tags" restrict a search to a particular part ("field") of a record, such as title, author or subject;

${ }^{\mathrm{b}} \mathrm{A}$ form of assessing/further populating the paper list

\section{Table 6 Categories of data analysed}

\begin{tabular}{|c|c|}
\hline \multirow{4}{*}{$\begin{array}{l}\text { Terminology and origin of } \\
\text { evidence }\end{array}$} & - Terminology (difference between peer-review and grey) \\
\hline & $\begin{array}{l}\text { - Type of evidence (i.e. case studies, experiments, modelling) and source (journal) and quality (see 'study } \\
\text { quality assessment' section) }\end{array}$ \\
\hline & - Proportion of articles looking at multiple adaptation options \\
\hline & $\begin{array}{l}\text { - Spread of evidence - geographic distribution and concentration of studies and field of study } \\
\text { (journal-type/theme) }\end{array}$ \\
\hline \multirow{3}{*}{$\begin{array}{l}\text { Aim of EbA-type activities } \\
\text { undertaken }\end{array}$} & - Climatic hazards and impacts addressed \\
\hline & - Adaptation target (e.g. sectors or individuals/groups/communities or both) \\
\hline & - Ecosystems being used/type of EbA interventions \\
\hline \multirow{4}{*}{$\begin{array}{l}\text { Measure of success and discussion } \\
\text { of limits }\end{array}$} & - Measures of effectiveness \\
\hline & - Result of adaptation intervention \\
\hline & - Time scale of effectiveness \\
\hline & - Biophysical thresholds and boundary conditions to effectiveness \\
\hline \multirow[t]{4}{*}{ Costs and benefits } & - Social, environmental and economic \\
\hline & - Cost-benefit to alternatives \\
\hline & - Temporal and spatial distribution of social, environmental and economic costs and benefits \\
\hline & - Trade-offs and synergies with land use and other ecosystem services \\
\hline \multirow{3}{*}{$\begin{array}{l}\text { Policy and institutions and } \\
\text { implementation }\end{array}$} & - Institutional effectiveness of adaptation interventions \\
\hline & - Intervention relationship with policy sphere and success of project in instigating policy change \\
\hline & - Design and implementation of projects \\
\hline
\end{tabular}


would be to extract the references that have provided the review paper with hard evidence;

${ }^{\mathrm{c}}$ These categories have been developed drawing upon the consensus categories used by the Intergovernmental Panel on Climate Change (IPCC) to determine level of scientific understanding of radiative forcing [http://www. ipcc.ch/publications_and_data/ar4/wg1/en/ch2s2-9-1. html].

\section{Additional file}

\section{Additional file 1: Excel blank logbook.}

\section{Competing interests}

The authors declare that they have no competing interests. be supported through a consultancy paid for by the United States Agency for International Development's (USAID) Sustainable Conservation Approaches in Priority Ecosystems (SCAPES) programme.

\section{Author details}

${ }^{1}$ BirdLife International, Wellbrook Court, Girton Road, Cambridge CB3 ONA, UK. ${ }^{2}$ International Institute for Environment and Development (IIED), 80-86 Gray's Inn Road, London WC1X 8NH, UK. ${ }^{3}$ UNEP-WCMC, 219 Huntingdon Road, Cambridge CB3 ODL, UK. ${ }^{4}$ Cambridge Coastal Research Unit, Department of Geography, University of Cambridge, Downing Place, Cambridge CB2 3EN, UK. ${ }^{5}$ Department of Geography, University of Cambridge, Downing Place, Cambridge CB2 3EN, UK. ${ }^{6}$ Department of Land Economy, University of Cambridge, 19 Silver Street, Cambridge CB3 9EP, UK. ${ }^{7}$ Research support provided by the United States Agency for International Development (USAID) through a consultancy, Ronald Reagan Building, 1300 Pennsylvania Ave. NW, Washington, DC 20523, USA.

Received: 3 April 2012 Accepted: 28 September 2012 Published: 5 November 2012

\section{References}

1. Secretariat of the Convention on Biological Diversity: Biodiversity and Climate-Change Adaptation. In Connecting Biodiversity and Climate Change Mitigation and Adaptation: Report of the Second Ad Hoc Technical Expert Group on Biodiversity and Climate Change, Technical Series, Volume 41. Montreal: Secretariat of the Convention on Biological Diversity; 2009:41.

2. Convention on Biological Diversity: X/33 Biodiversity and climate change, Decision Adopted by the Conference of the Parties to the Convention on Biological Diversity at its Tenth Meeting; UNEP/CBD/COP/DEC/x/33; 29 October 2010. Nagoya, Japan: Secretariat of Convention on Biological Diversity; $2010: 2$

3. Colls A, Ash N, Ikkala N: Ecosystem-based Adaptation: a natural response to climate change. Gland, Switzerland: IUCN; 2009.

4. BirdLife International: Partners with nature: how healthy ecosystems are helping the world's most vulnerable adapt to climate change. Cambridge: BirdLife International; 2009.

5. Reid H, Swiderska K: Biodiversity, climate change and poverty: exploring the links. London: IIED; 2008.

6. Ecosystems and Livelihoods Adaptation Network (IUCN, WWF, CARE, IIED) case studies: good practices. www.elanadapt.net/good-practices.

7. Reid H: Improving the evidence for ecosystem-based adaptation. Sustainable Development Opinion Paper. London: IIED; 2011.

8. UNFCCC Secretariat: Synthesis report on efforts undertaken to assess the costs and benefits of adaptation options, and views on lessons learned, good practices, gaps and needs, FCCC/SBSTAV2010/3: 22 March 2010. Bonn: UNFCCC Secretariat; 2010:5.

9. Brooks N, Anderson S, Ayers J, Burton I, Tellam I: Tracking Adaptation and Measuring Development. IIED Climate Change Working Paper No.1. London: IIED; 2011.

10. Spearman M, McGray H: Making Adaptation Count: Concepts and Options for Monitoring and Evaluation of Climate Change Adaptation. Eschborn: The Deutsche Gesellschaft für Internationale Zusammenarbeit (GIZ); 2011.

11. Lamhauge N, Lanzi E, Agrawala S: Monitoring and Evaluation for Adaptation: Lessons from Development Co-operation Agencies, OECD Environment Working Papers, No.38. OECD Publishing. 2011 http://dx.doi.org/10.1787/5kg20mj6c2bw-en.

12. Adaptation Fund: Project level results framework and baselines guidance. http://www.adaptation-fund.org/sites/default/files/Results\%20Framework\% 20and\%20Baseline\%20Guidance\%20final.pdf.

13. Intergovernmental Panel on Climate Change: Climate Change 2007: Synthesis report. Contributions of working groups I, II and III to the fourth assessment report of the IPCC. Geneva, Switzerland: IPCC; 2007.

14. Center for Evidence-Based Conservation: Guidelines for systematic review in the environmental management, Version 4.0. Environmental Evidence. Bangor: Centre for Evidence-Based Conservation; 2010:37-38.

15. Jasco P: As we may search - Comparison of major features of the Web of Science, Scopus, and Google Scholar citation-based and citationenhanced databases. Current Contents 2005, 89(9):1537-1547.

16. Kappa test online calculator. http://www.chestx-ray.com/Statistics/kappa. html. 
17. Munroe R, Doswald N, Roe D, Reid H, Giuliani A, Castelli I: Framework for Assessing the Evidence for the Effectiveness of Ecosystem-based Approaches to Adaptation. Cambridge: BirdLife International, UNEP-WCMC, IIED; 2011 http://elanadapt.net/sites/default/files/siteimages/cci_and_elan_framework. pdf.

18. Pilot Programme for Climate Resilience (PPCR): Results Framework. PPCR/ SC.7/7: 28 October 2010. Washington DC: Meeting of the PPCR Sub-Committee, Climate Investment Funds; 2010.

19. Africa Climate Change Resilience Alliance: Consultation Document: [Draft] The ACCRA Local Adaptive Capacity Framework (LAC). Kampala: Oxfam GB 2010 http://community.eldis.org/.59d669a7/LACFconsult.pdf.

20. Munroe R, Doswald N, Roe D, Reid H, Giuliani A, Castelli I: Guidance on Applying the Framework for Assessing the Evidence for the Effectiveness of Ecosystem-based Approaches to Adaptation. Cambridge, UK: BirdLife International, UNEP-WCMC, IIED; 2011.

doi:10.1186/2047-2382-1-13

Cite this article as: Munroe et al:: Review of the evidence base for ecosystem-based approaches for adaptation to climate change.

Environmental Evidence 2012 1:13

\section{Submit your next manuscript to BioMed Central and take full advantage of:}

- Convenient online submission

- Thorough peer review

- No space constraints or color figure charges

- Immediate publication on acceptance

- Inclusion in PubMed, CAS, Scopus and Google Scholar

- Research which is freely available for redistribution 